\title{
Social outcomes in children with autism spectrum disorder: a review of music therapy outcomes
}

This article was published in the following Dove Press journal:

Patient Related Outcome Measures

20 February 2017

Number of times this article has been viewed

\author{
A Blythe LaGasse \\ School of Music, Theatre \& Dance, \\ Colorado State University, Fort \\ Collins, CO, USA
}

\begin{abstract}
Autism spectrum disorder (ASD) affects approximately one in 68 children, substantially affecting the child's ability to acquire social skills. The application of effective interventions to facilitate and develop social skills is essential due to the lifelong impact that social skills may have on independence and functioning. Research indicates that music therapy can improve social outcomes in children with ASD. Outcome measures are primarily assessed using standardized nonmusical scales of social functioning from the parent or clinician perspective. Certified music therapists may also assess musical engagement and outcomes as a part of the individual's profile. These measures provide an assessment of the individual's social functioning within the music therapy session and generalizability to nonmusical settings.
\end{abstract}

Keywords: autism spectrum disorder, music therapy, social skills

\section{Introduction}

Autism spectrum disorder (ASD) is a pervasive neurodevelopmental disorder that affects one in 68 children. ${ }^{1}$ Core characteristics of ASD include lack of social and communication skills, as well as repetitive and restricted behaviors. ${ }^{2}$ There is continued need for evidence-based treatment methods for children with ASD, with only 14 established practices for children and one established practice for adults according to the National Autism Center's National Standards Project. ${ }^{3}$ Music therapy has been recommended as an effective treatment intervention for social interaction, verbal communication, and socioemotional reciprocity. ${ }^{4}$ The unique stimulus of music provides an engaging way for children with ASD to interact socially and work toward nonmusical social outcomes.

\section{Treatment of autism}

Treatment of individuals with ASD can be difficult due to the spectrum nature of the diagnosis. Children with ASD display a range of skills in social communication and behaviors, making individualized treatment necessary. There are three levels of autism: Level 1 - requiring support; Level 2 - requiring substantial support; and Level 3 - requiring very substantial support. ${ }^{2}$ Although $\sim 44 \%$ of persons with ASD have average intellectual ability, $\sim 83 \%$ of persons with ASD have co-occurring developmental, neurological, genetic, or chromosomal disabilities. ${ }^{1}$ The average medical costs for persons with ASD are 4.1-6.2 times higher than for those without ASD, with estimates of behavioral interventions costing US $\$ 40,000-60,000 /$ year per child. ${ }^{1}$ These factors indicate that children with ASD have substantial treatment needs. Economic
Correspondence: A Blythe LaGasse School of Music, Theatre \& Dance, Colorado State University, 1778 Campus Delivery, Fort Collins, CO 80523, USA Tel + I 97049 I 4042

$\mathrm{Fax}+\mathrm{I} 9704917541$

Email Blythe.LaGasse@colostate.edu 
factors and differences in level of diagnosis necessitate the use of evidence-based practices and strategies that can best facilitate individual outcomes.

Children with ASD have difficulty with social interaction behaviors, including establishing and maintaining relationships, reciprocating social interaction, and communicating with others. ${ }^{2}$ Lack of social skills may have lifelong implications for children with ASD, affecting their family/ community interactions, academic skills, self-worth, and independence. Reports on social skills in ASD indicate that these skills are extremely difficult to learn ${ }^{5}$ and that educational objectives should be focused on developing social skills because they have lifelong implications. ${ }^{6}$ Therefore, there is a need for effective interventions targeting social outcomes in children with ASD who have differing levels of functioning and abilities.

Many different treatments and practices address social skills in children with ASD. The National Autism Council's National Standards Report categorizes peer training, joint attention, and behavioral package interventions as "established" practices for addressing social skills. ${ }^{3}$ In a review of research addressing social skills in ASD, investigators identified video modeling and social skills-based group interventions as evidence-based practices. ${ }^{7,8}$ Chang and Locke ${ }^{9}$ found that peer-mediated interventions, in which typical peers provide a social model, were also promising interventions for improvising social skills. Although the literature includes several practices and interventions that directly or indirectly target social skills, there is no conclusive evidence that one method of treatment is effective for developing social skills in children with ASD. Music may also be used to address social skills in children with ASD and research evidence has indicated that music therapy interventions can successfully promote social skills. ${ }^{4}$

\section{Music therapy}

Music therapy is defined by the American Music Therapy Association as the "clinical and evidence-based use of music interventions to accomplish individualized goals within a therapeutic relationship by a credentialed professional who has completed an approved music therapy program." 10 Professional music therapists hold a bachelor's degree or higher in music therapy. Degree programs focus on musical foundations, clinical foundations, and music therapy foundations and principles. ${ }^{11}$ The bachelor's degree also requires 1200 hours of clinical training, inclusive of a supervised clinical internship. The professional credential of Music Therapist-Board Certified (MT-BC) is obtained by sitting for the national board certification examination. ${ }^{11}$
Music therapy professionals develop music-based interventions that facilitate social, communicative, motor/sensory, emotional, cognitive, and music skills in individuals. Music therapy services are individualized to the person's preferences and abilities, and these can be provided in partnership with families and treatment teams. ${ }^{12}$ Music therapy can be used with people of different socioeconomic backgrounds, cultures, and ages and may be provided in schools, home, music therapy clinic, or hospital. ${ }^{12}$

The music therapy assessment process is used to determine the individual's current level of functioning and the appropriateness of music therapy as a treatment. This process involves the application of intentional and developmentally appropriate music experiences. ${ }^{12}$ Following the assessment, the music therapy professional designs a treatment plan that outlines interventions that will be used to target areas of need. Although there are defined protocols within different approaches in music therapy, ${ }^{13}$ the music therapy clinician adapts protocols to best promote the individual's treatment needs. Furthermore, music therapy interventions can be combined with evidence-based strategies, including reinforcement, prompting, and picture schedules. ${ }^{12}$ Due to the highly individualized treatment approach, clinicians may address the needs of children with different levels of ASD, including children with comorbid diagnoses.

\section{Music therapy for social skills in children with autism}

There is a long history of the use of music and music therapy services to help individuals with ASD achieve nonmusical goals, including social skills. ${ }^{14}$ Clinical writings and research on the use of music therapy show the various approaches to treatment with music. Clinicians and researchers have investigated the impact of music therapy from behavioral, ${ }^{15}$ relationship-centered, ${ }^{16}$ applied behavior analysis-based, ${ }^{17}$ family-centered, ${ }^{18}$ social communication-emotional regulation-transactional support (SCERTS) model-based, ${ }^{19,20}$ improvisational, ${ }^{21}$ and neurological ${ }^{22}$ approaches to facilitate social skills and communication. Therefore, there are many different approaches and interventions that can be used to target social skills in music therapy. One commonality between these approaches is the use of musical stimuli and musical engagement to provide a foundation for enhanced socialization in children with ASD, leading to improved nonmusic social skills.

Music therapy is a unique treatment approach that uses music experiences that can engage children in meaningful interactions with others. Many children with ASD respond positively to music experiences, making music a safe and 
structured stimulus for social engagement and the practice of social skills. There are several reasons that musical stimuli may help with developing social skills. Music has been demonstrated to activate neural networks involved in similar musical and nonmusical tasks (eg, speech and singing both activate the left inferior frontal gyrus $)^{23,24}$ and further has the ability to optimize target behaviors through synchronized neural firings. ${ }^{25}$ Specific to persons with ASD, initial research has demonstrated a unique attraction to musical stimuli and enhanced musical ability, ${ }^{26-29}$ with some evidence of neurological reactions similar to those of a musician when involved in music. ${ }^{30}$ Further, adults with ASD are shown to have intact processing of musical emotions. ${ }^{31}$ These data indicate that music in treatment may provide a strong basis for learning social skills that may then be generalized into a nonmusical context.

In addition to enhanced processing of music in persons with ASD, the mechanisms of musical stimuli may provide a foundation for learning social skills. The rhythmic and structural components of musical stimuli provide an external cue or anchor to further help children with ASD to organize, predict, and respond. A lack of neural organization in children with ASD may prevent children with ASD from appropriately responding to their environment due to difficulties with sensory overload, planning, initiation, and completing motor sequences. ${ }^{32,33}$ Because social skills require the ability to plan, initiate, and follow through with complex motor plans, this lack of organization could affect a person's ability to engage socially. Rhythm and music may provide a unique accommodation for these deficits, as musical stimulus is highly predictable and has been widely shown to help with planning and execution of motor patterns. ${ }^{34,35}$ Structured musical experiences can be created to specifically provide clear cues for the anticipation and planning of a response, thereby facilitating social interaction. Music cues can also be used to assist with waiting/impulse control during a social experience, with music structure outlining the social response time of the peer. Therefore, the characteristics of the musical experience serve as a structure for completing social interactions.

Although musical stimuli provide a clear time-based structure, music exploration is also inherently flexible, as musical improvisations can use different tonalities, harmonies, melodies, phrase lengths, motives, and structure. For example, the use of strict structure can be provided to help with anticipation of a back-and-forth communication, while improvisation within a certain modality (ie, major or minor key) and the use of different melodic themes on a pitched instrument allow for creativity. Within this experience, rhythm may be held constant in order to promote the anticipation and timing of musical communication, supporting the overall social interaction. This musical experience, wherein the client and therapist may be passing musical phrases back and forth, provides a means for practicing social interaction within a structure that provides accommodations to promote success. For example, this experience could be completed with school-aged children with ASD who have little to no verbal language, providing a nonverbal means for practicing social engagement, turn taking, joint attention, and other fundamental social skills.

Music therapy interventions are indicated to have positive effects on social skills, including increased engagement behavior, ${ }^{36}$ increased emotional engagement, ${ }^{37}$ and improved social interaction. ${ }^{38,39}$ Researchers have also indicated that music therapy can increase social greeting routines,${ }^{40}$ joint attention behaviors, ${ }^{21,22}$ peer interactions,${ }^{41}$ communication skills, ${ }^{15,17,42}$ and cognitive social skills. ${ }^{43}$ These studies provide evidence that music therapy can promote measurable changes in the social behaviors of children with ASD.

Although music therapy interventions can promote social skills in individuals with ASD, there is continued need for larger-scale research, as many studies focused on music therapy for social skills comprise a single-subject design or are case studies. Furthermore, there are unique challenges to outcome measurement in music therapy. Most music therapy professionals use standardized scales or published observational scales as a part of pretest and posttest measurement of outcomes. These scales provide information about generalization of skills; however, they may not accurately reflect changes that are occurring within music experiences. Researchers have also used observation of behaviors within the sessions to determine whether children with ASD demonstrate more social interactions when engaged in musical experiences. Social behavior has also been investigated in terms of musical engagement, with observational behavior recording during the music therapy treatment sessions or on completion of a music therapy assessment scale. In the following section, the unique aspects of outcome measurement for social skills in children with ASD are discussed.

\section{Promoting social outcomes in children with ASD \\ Assessment}

Assessment and diagnosis of individuals with ASD rely heavily on parental interview, cognitive/developmental assessment, observation, and a comprehensive medical evaluation. ${ }^{3}$ 
Common assessments include interview assessments such as the Childhood Autism Rating Scale (CARS), ${ }^{44}$ the Autism Diagnostic Interview-Revised, ${ }^{45}$ and the Autism Diagnostic Observation Schedule. ${ }^{46}$ Music therapists do not diagnose disorders; however, music may provide unique insights within the assessment process for individuals with ASD.

Clinical assessment in music therapy serves two functions, namely, to track the functioning level of the client during the course of treatment and to determine the optimal selection of treatment protocols. ${ }^{47}$ Music therapy clinicians document progress within music therapy sessions ${ }^{48}$ and also use standardized clinical assessment tools. ${ }^{47}$ By using nonmusical assessment tools that are valid and reliable, the music therapy clinician can determine whether the client's functioning level is improving and whether they are meeting appropriate benchmarks. ${ }^{47}$

One difficulty in assessing social skills in children with ASD is that many of the nonmusical assessment tools that are readily available consist of subjective scales of behavior (such as the CARS). Other scales may be training or time prohibitive (such as Autism Diagnostic Observation Schedule). Therefore, in order to determine whether gains are being made as a result of music therapy treatment, the music therapy professional may use a combination of assessment tools, including parent-report scales (such as the Autism Treatment Evaluation Checklist), clinician-based observation scales (such as the Functional Emotional Assessment Scale), clinical session data documentation, interview, or observation of the client across different settings. As many music therapists are members of a larger interdisciplinary treatment team, ${ }^{48}$ observations from other professionals may inform the music therapist as to the generalization of skills in other settings.

Music therapists also use musical materials in order to assess nonmusical functioning, including social skills. As a form of alternative communication and play, assessment in music interactions may show social reciprocity, social engagement, responsiveness, and verbal/nonverbal interactions. ${ }^{49}$ Because many children with ASD are attracted to musical stimuli, music can be used to further assess core characteristics of ASD. ${ }^{49,50}$ There are also two music-based assessments that have been developed and tested for validity and reliability.

The Music-based Autism Diagnostics (MUSAD) was developed specifically to assess functioning in adults with intellectual disability who may also have ASD. ${ }^{50}$ The assessment was developed to assess the ICD-10 characteristics of ASD, with the DSM-5 characteristics also integrated. The assessment has sections for social integration, communication, stereotyped and repetitive behaviors, sensory-motor issues, and affective dysregulation (including temper tantrums and aggression). The assessment has two forms - one for individuals who are verbal and one for individuals who are nonverbal. One benefit of the music-based assessment is the feasibility of individuals completing the assessment, which has been shown to be $95 \%$ for the MUSAD. ${ }^{51}$ The MUSAD uses specific music interactions in order to assess the behavioral areas and was found to have high validity and reliability. ${ }^{50,51}$

A second music-based assessment for children with ASD is the Individual Music-Centered Assessment Profile for Neurodevelopmental Disorders (IMCAP-ND). ${ }^{52}$ This assessment is from a relationship-based developmental framework, whereby the assessment rates the individual's ability to perceive, interpret, and create music with the therapist. ${ }^{52}$ Further, this assessment is from a music-centered treatment perspective, providing insights as to how the individual is functioning in music, which can better inform nonmusical interactions and understanding. For example, the individual is rated on their focus, sharing, interactions, affect, and initiations within the musical experiences. Although these musical assessments are no replacement for formal diagnostic procedures, the assessments may be useful to help identify a person's unique strengths and abilities within a more creative and motivating nonverbal form of interaction.

\section{Outcomes from a parental perspective}

Parent questionnaires have frequently been used to determine the impact of music therapy treatment on children with ASD. Parental questionnaires are commonly used in music therapy research because the participants in the studies are often children who may not have verbal or cognitive skills to report on their own perceptions of their abilities. Scales used in the literature include the Social Responsiveness Scale (SRS), ${ }^{53}$ the Autism Treatment Evaluation Checklist, ${ }^{54}$ Vineland Social-Emotional Early Childhood Scales, ${ }^{55}$ and the Parent-Child Relationship Inventory. ${ }^{56}$ Social communication has been quantified using the MacArthur-Bates Communicative Development Inventories. $^{57}$

Social interaction skills have been shown to improve due to group music therapy intervention compared to a control group condition based on parental completion of the SRS. ${ }^{22}$ Significant improvements have also been indicated with the 
Vineland Social-Emotional Childhood Scales in a study of individualized family-centered music therapy (FCMT). ${ }^{18}$ Parental reports can be essential to understanding the generalizability of learned skills; however, there is the potential for parent bias, because there was no blinding of the treatment received in these studies. Despite the potential for bias, parental report may reflect how meaningful and relevant treatment is to the family unit. ${ }^{4}$

Parental opinion of music therapy for social and relationship outcomes has also been reported using qualitative research in which parents are involved in interviews and/or focus groups. These studies indicate that music therapy interventions that involve the family can have a positive impact on the parent-child relationship in both the individual and group settings. ${ }^{58,59}$ Table 1 illustrates the range of parental-report tools used to evaluate the effect of music therapy interventions from a sampling of the music therapy literature.

\section{Outcomes from a clinician perspective}

Social interaction skills in music therapy treatment studies have been investigated using published scales of social behavior. Most of these scales are completed outside of the therapeutic contexts as pre- and posttest measures, potentially indicating generalization of skills outside the treatment session. Further, these scales have been completed by professionals who are otherwise uninvolved with the study in order to limit researcher bias in completing these tools ${ }^{60}$ or raters who are blinded to the participant's group. ${ }^{21,61}$ Scales used in the literature include the CARS, ${ }^{44}$ the Pervasive Developmental Disorder Behavior
Inventory (PDD-BI), ${ }^{62}$ and the Early Social Communication Scales. ${ }^{63}$ The results of music therapy studies indicated that social skills for nonverbal children with ASD improved based on the CARS-Brazilian version (BR) scale,${ }^{61}$ the Early Social Communications Scale, ${ }^{21}$ the social subscale of PDD-BI, ${ }^{21}$ and the Functional Emotional Assessment Scale. ${ }^{16}$

Observational data have also been collected and coded in order to determine social behaviors during or after music therapy treatment sessions. The number of instances of receptive or initiated joint attention bids has been shown to increase both during ${ }^{22}$ and after music therapy interventions. ${ }^{64}$ Eye gaze and eye contact have also been shown to improve during music therapy sessions using observational measures. ${ }^{22,65}$ One study also demonstrated improvements in imitation and turn taking during music therapy intervention sessions. ${ }^{65}$ Children with ASD who are engaged in music therapy interventions have also shown improvements in joint attention and focusing on faces outside of the music therapy session. ${ }^{64}$ Table 2 illustrates the range of clinician-report tools used to evaluate the effect of music therapy interventions from a sampling of the music therapy literature. Table 3 illustrates the use of observational measures to evaluate the effect of music therapy interventions from a sampling of the music therapy literature.

\section{Music-centered outcome measures}

Although most studies on the use of music therapy for social skills in children with ASD rely on standardized or gold standard assessments of nonmusical skills, some researchers have approached outcome assessment from a music-centered

Table I Range of parental-report tools used to evaluate the effect of music therapy interventions

\begin{tabular}{|c|c|c|c|c|c|c|}
\hline Author & Group/individual & Design & $\begin{array}{l}\text { Final number of } \\
\text { participants }\end{array}$ & Sex & $\begin{array}{l}\text { Age, } \\
\text { years }\end{array}$ & $\begin{array}{l}\text { Parent-reported scales } \\
\text { used }\end{array}$ \\
\hline Allgood ${ }^{59}$ & Group with families & One group & $N=4$ & $F=2 ; M=2$ & $4-6$ & Interview and focus groups \\
\hline Geretsegger et $\mathrm{al}^{80}$ & Individual & $\begin{array}{l}\text { Feasibility of } \\
\text { randomized } \\
\text { controlled trial }\end{array}$ & $\begin{array}{l}N=15 ; \text { high-dose treatment } \\
(n=4) ; \text { low-dose treatment } \\
(n=3) ; \text { control }(n=8)\end{array}$ & $F=4 ; M=I I$ & $4-6$ & Social Responsiveness Scale \\
\hline LaGasse $^{22}$ & Group & $\begin{array}{l}\text { Randomized } \\
\text { control trial }\end{array}$ & $\begin{array}{l}N=17 ; \text { treatment } \\
(n=9) ; \text { control }(n=8)\end{array}$ & $F=4 ; M=13$ & $6-9$ & $\begin{array}{l}\text { Social Responsiveness Scale; } \\
\text { Autism Treatment Evaluation } \\
\text { checklist }\end{array}$ \\
\hline Thompson et al ${ }^{18}$ & Individual with family & $\begin{array}{l}\text { Randomized } \\
\text { controlled trial }\end{array}$ & $\begin{array}{l}N=2 I ; \text { treatment }(n=I I) \\
\text { control }(n=10)\end{array}$ & Not reported & $3-6$ & $\begin{array}{l}\text { Vineland Social-Emotional } \\
\text { Childhood Scales (VSEEC); } \\
\text { Social Responsiveness Scale - } \\
\text { Preschool; MacArthur-Bates } \\
\text { Communicative Development } \\
\text { Inventories; The Parent- } \\
\text { Child Relationship Inventory }\end{array}$ \\
\hline $\begin{array}{l}\text { Thompson and } \\
\text { McFerran } \\
\text { M8 }^{58}\end{array}$ & Individual with family & One group & $N=I I$ & Not reported & $3-6$ & Interview \\
\hline
\end{tabular}

Abbreviations: $F$, female; $M$, male. 
Table 2 Range of clinician-based observation tools used to evaluate the effect of music therapy interventions

\begin{tabular}{|c|c|c|c|c|c|c|}
\hline Author & $\begin{array}{l}\text { Group/ } \\
\text { individual }\end{array}$ & Design & $\begin{array}{l}\text { Final number of } \\
\text { participants }\end{array}$ & Sex & $\begin{array}{l}\text { Age, } \\
\text { years }\end{array}$ & $\begin{array}{l}\text { Clinician-based } \\
\text { observation scales }\end{array}$ \\
\hline Carpente $^{16}$ & Individual & Case study & $N=4$ & $F=2 ; M=2$ & $4-8$ & $\begin{array}{l}\text { Functional Emotional } \\
\text { Assessment Scale (FEAS) }\end{array}$ \\
\hline Kim et $\mathrm{al}^{21}$ & Individual & $\begin{array}{l}\text { Repeated measures } \\
\text { within subject } \\
\text { design }\end{array}$ & $N=10$ & $F=0 ; M=10$ & $3-5$ & $\begin{array}{l}\text { Early Social Communication } \\
\text { Scales; Pervasive } \\
\text { Developmental Disorder } \\
\text { Behavior Inventory-C }\end{array}$ \\
\hline Geretsegger et $\mathrm{al}^{80}$ & Individual & $\begin{array}{l}\text { Feasibility of } \\
\text { randomized } \\
\text { controlled trial }\end{array}$ & $\begin{array}{l}N=15 ; \text { high-dose treatment } \\
(n=4) ; \text { low-dose treatment } \\
(n=3) ; \text { control }(n=8)\end{array}$ & $F=4 ; M=11$ & $4-6$ & $\begin{array}{l}\text { Autism Diagnostic } \\
\text { Observation Scale - } \\
\text { Social Affect }\end{array}$ \\
\hline
\end{tabular}

Abbreviations: F, female; M, male.

Table 3 Range of clinician-based observation tools used to evaluate the effect of music therapy interventions

\begin{tabular}{|c|c|c|c|c|c|c|}
\hline Author & $\begin{array}{l}\text { Group/ } \\
\text { individual }\end{array}$ & Design & $\begin{array}{l}\text { Number of } \\
\text { participants }\end{array}$ & Sex & $\begin{array}{l}\text { Age, } \\
\text { years }\end{array}$ & Observation measures \\
\hline $\begin{array}{l}\text { Finnigan and } \\
\text { Starr }{ }^{65}\end{array}$ & Individual & $\begin{array}{l}\text { Single case alternating } \\
\text { treatment design }\end{array}$ & $N=I$ & $\mathrm{~F}$ & 3 & Eye contact, turn taking, imitation \\
\hline $\begin{array}{l}\text { Kern and } \\
\text { Aldridge }\end{array}$ & Individual & $\begin{array}{l}\text { Single system multiple } \\
\text { baseline }\end{array}$ & $N=4$ & $M=4$ & $3-5$ & $\begin{array}{l}\text { Play/engagement and interaction } \\
\text { with peers }\end{array}$ \\
\hline Kern et al ${ }^{40}$ & Individual & $\begin{array}{l}\text { Single system } \\
\text { withdrawal design }\end{array}$ & $N=2$ & $M=2$ & 3 & $\begin{array}{l}\text { Independent and prompted } \\
\text { responses }\end{array}$ \\
\hline Kim et $\mathrm{al}^{21}$ & Individual & $\begin{array}{l}\text { Repeated measures } \\
\text { within subject design }\end{array}$ & $N=10$ & $M=10$ & $3-5$ & $\begin{array}{l}\text { Instances of eye contact, as well as } \\
\text { turn-taking frequency and duration }\end{array}$ \\
\hline Kim et $\mathrm{al}^{37}$ & Individual & $\begin{array}{l}\text { Repeated measures } \\
\text { within subject design }\end{array}$ & $N=10$ & $M=10$ & $3-5$ & $\begin{array}{l}\text { Motivational responsiveness and } \\
\text { social responsiveness }\end{array}$ \\
\hline LaGasse $^{22}$ & Group & $\begin{array}{l}\text { Randomized } \\
\text { controlled trial }\end{array}$ & $\begin{array}{l}N=17 ; \text { treatment } \\
(n=9) ; \text { control }(n=8)\end{array}$ & $\begin{array}{l}F=4 ; M \\
=13\end{array}$ & $6-9$ & $\begin{array}{l}\text { Instances of joint attention, } \\
\text { initiating, responding, and social } \\
\text { eye gaze }\end{array}$ \\
\hline Pasiali et a ${ }^{78}$ & Individual & Case study & $N=3$ & $F=1 ; M=2$ & $7-9$ & $\begin{array}{l}\text { Behaviors observed to be different } \\
\text { for each child, based on needs }\end{array}$ \\
\hline Vaiouli et al ${ }^{64}$ & Individual & $\begin{array}{l}\text { Single system multiple } \\
\text { baseline design }\end{array}$ & $N=3$ & $F=1 ; M=2$ & $5-7$ & $\begin{array}{l}\text { Focus on faces, response to joint } \\
\text { attention, and initiation of joint } \\
\text { attention }\end{array}$ \\
\hline
\end{tabular}

Abbreviations: $F$, female; $M$, male.

perspective. Assessment of musical engagement and musical interactions can provide information about how the child engages with musical stimuli and how this fits into a developmental framework.

The Music Therapy Diagnostic Assessment (MTDA) ${ }^{66}$ was used as a secondary outcome measure to determine engagement within music therapy sessions. ${ }^{18}$ In particular, this scale measured the child's social communication and interpersonal engagement. This measure indicated a significant positive difference for children engaged in music therapy sessions. ${ }^{18}$

Music skills have also been included as a variable to determine whether engagement in music would affect musical milestones and absorption of music. One study found that children with ASD who participated in 52 weekly music therapy sessions increased their ability to sing melodies, play a musical scale, and reproduce simple and complex rhythmic patterns..$^{60}$ These changes were accompanied by changes in standardized scores, including scores on the Clinical Global Impression (CGI) scale and the Brief Psychiatric Rating Scale (BPRS). ${ }^{67,68}$ Although music skills are not commonly tested in music therapy studies, changes in music skills could have implications for inclusion in music education classrooms or overall engagement in music-making experiences. Table 4 illustrates the use of musical measures to evaluate the effect of music therapy interventions from a sampling of the music therapy literature.

\section{Strategies for improved outcomes}

The purpose of music therapy services is to use specific musical stimuli in order to promote nonmusical skills through music experiences. Music therapy interventions may include improvisation, precomposed music, and/ or active music-making experiences that promote skills 
Table 4 Range of music-based tools used to evaluate the effect of music therapy interventions

\begin{tabular}{|c|c|c|c|c|c|c|}
\hline Author & Group/individual & Design & Number of participants & $\begin{array}{l}\text { Age, } \\
\text { years }\end{array}$ & Sex & $\begin{array}{l}\text { Music-centered scale } \\
\text { or observation }\end{array}$ \\
\hline Boso et al ${ }^{60}$ & Group & One group & $N=8$ & $23-38$ & $F=I ; M=7$ & $\begin{array}{l}\text { Musical skills (playing } \\
\text { scales, singing melody, } \\
\text { and reproducing rhythm) }\end{array}$ \\
\hline Kim et $\mathrm{al}^{21}$ & Individual & $\begin{array}{l}\text { Repeated measures } \\
\text { within subject design }\end{array}$ & $N=10$ & $3-5$ & $M=10$ & $\begin{array}{l}\text { Musical synchrony } \\
\text { (observation) }\end{array}$ \\
\hline Thompson et al ${ }^{18}$ & Individual with family & $\begin{array}{l}\text { Randomized } \\
\text { controlled trial }\end{array}$ & $\begin{array}{l}N=21 ; \text { treatment }(n=11) ; \\
\text { control }(n=10)\end{array}$ & $3-6$ & Not reported & $\begin{array}{l}\text { The Music Therapy } \\
\text { Diagnostic Assessment }\end{array}$ \\
\hline
\end{tabular}

Abbreviations: $F$, female; $M$, male.

including communication, social interaction, motor skills, and cognition. Music therapy research has long focused on social skills as one area of treatment and the unique aspects of music interaction have been shown to help individuals with ASD to engage socially. ${ }^{14}$ Although more research is needed on the use of music therapy for social outcomes in individuals with ASD, the extant literature shows positive improvements in social responsiveness, communication, and joint attention skills.

Researchers have demonstrated that persons with ASD often have unique attraction to music and may have enhanced musical abilities..$^{31,69,70}$ This attraction to music can be used to engage children with ASD in musical experiences that can facilitate social skills. In these experiences, engagement is promoted through interactions with musical stimuli but also with the music therapist who is crafting musical stimuli that will engage the child. Peers (with ASD or neurotypical) or parents are often involved in the sessions to promote social skills within the family or peer group. Several types of music therapy interventions and approaches have demonstrated increased social engagement, including improvisational music therapy and neurological-based group music therapy.

Improvisational music therapy has been shown to increase joint attention, social-emotional skills, social engagement, and nonverbal social communication. ${ }^{16,21,37,71}$ Children involved in improvisational music therapy experiences are actively engaging in interactive live music-making experiences. The music therapist will follow the client's musical lead, creating spontaneous music to engage musical and nonmusical responses. ${ }^{72}$ The music therapist can then change the music, creating music that can directly engage the clients in order to promote their therapeutic needs (such as social skills). In addition to overall social engagement, researchers have reported more instances of "joy" and "emotional synchronicity" when children with ASD are engaged in improvisational music therapy compared to play. ${ }^{37}$ Therefore, the positive and naturally engaging experience of making music serves as the foundation on which the nonmusical skills are practiced and learned. Improvisation in music therapy has also been combined with general treatment models, including family-centered practice and the Developmental, Individual difference, Relationship-based Floortime (DIRFloortime ${ }^{\circledR}$ ) model. $^{73}$

FCMT has been applied by music therapy professionals to improve engagement within the community and with the child-parent relationship. ${ }^{18,58,59}$ FCMT incorporates exercises that promote parent-child relationships using music as a way to engage the child in the experiences. Therefore, this approach is supporting both the parent-child relationship and skill development. ${ }^{18}$ The music therapist works in collaboration with the parents in order to facilitate active interaction with their children. ${ }^{74}$ Exercises used within an FCMT session may include a greeting song to orient the parent and child to the session, structured improvisations whereby the music therapist may play a predictable harmonic structure and pause for the child to respond, structured instrument games, and/or songs with props. ${ }^{18}$ Principles of FCMT are outlined by Thompson. ${ }^{74}$ This approach in treatment may be more beneficial for children with ASD who are still developing interaction skills with their families.

Child-centered and relationship-based improvisational music therapy has also been shown to increase joint engagement in children with ASD. ${ }^{16,64,75}$ A full report on how music has been used within the DIRFloortime is outlined in the case studies paper by Carpente. ${ }^{16}$ One example of music therapy intervention from the DIRFloortime approach is the two-way purposeful musical play, whereby the music therapist improvises music that offers space for a response, engaging the child in a back-and-forth musical interaction. The spontaneous creation of music helps to first engage the child and then allows the child to respond to the therapist's crafting of musical questions, thus increasing social engagement. ${ }^{16}$ Similar to FCMT, this approach may be best suited for children with ASD who are attracted to music making and have needs in areas of social engagement and social interaction skills. 
Although the specific approach in each of these aforementioned music therapy interventions varies, the unifying factor is the use of engaging musical experiences to help promote social engagement. Along with the musical stimuli, the interactions are at the core of each of these experiences. Musical engagement may be essential for the improvement of social skills, as simply introducing musical materials has not been shown to increase social engagement. ${ }^{41}$ Further, simply presenting music in the environment has not been shown to have an effect on engagement of children with ASD. ${ }^{76}$ Therefore, the combination of clinically selected music within a social experience is needed for increased social engagement.

Music therapy clinicians developing musical experiences for joint attention must consider many factors of the experience, including the age of the clients, level of ASD, and presenting behaviors. Unique to music therapy treatment, the clinician must consider the type of music that will be used, as the style and/or complexity of the music may affect responses. For example, Kalas ${ }^{77}$ found that more complex music was the most effective musical stimulus for eliciting joint attention in children with mild/moderate ASD. Conversely, children with severe ASD demonstrated greater joint attention with less complex music. Therefore, the role of the music therapist is to determine what type of music and music materials promotes joint attention skills and then to use those materials within social experiences that provide the person with ASD the opportunities to practice joint attention.

Musical materials and experiences have been shown to be superior to nonmusical materials in the promotion of joint attention..$^{21,22}$ In one study, children with ASD were engaged in music-making experiences that promoted joint engagement with a peer with ASD. Researchers coded for triadic joint attention that was receptive or initiated. Music therapy experiences included playing instruments, where triadic joint attention was between two child peers and an instrument. The music therapist provided structure using an original song that contained lyrics for the steps of joint attention to the peer and the instrument. In this case, the instrument is a desired object and the reference to another person/participation in musical play continues the engagement with an item and another person in the room. The musical experience is rewarding and can therefore be used to promote or reinforce the desired social skill. The researchers noted that in the play group, the observational data indicated that the children spent more time occupied with the tools in the room (such as game pieces) than referencing their peer as a part of the social experience. ${ }^{22}$ Therefore, the clinically intentioned music adds a scaffold for the desired behavior and that structure can be faded as the children gain intended skills.
Music therapy interventions have also been shown to improve cognitive and emotional processing skills that may directly affect social skills. Initial evidence indicated that a music therapy protocol increased selective and alternating attention in children with neurodevelopmental disorders, including ASD ${ }^{78}$ Speech communication was shown to increase in children receiving music therapy interventions, with the greatest benefit for children who exhibited low verbal skills. ${ }^{15}$ Music therapy interventions have also been shown to improve emotional understanding, ${ }^{79}$ which may affect a person's ability to relate to another person. Music interventions have also been shown to improve motor initiation and sequencing, ${ }^{35}$ affecting a person's ability to initiate, sustain, or complete motor movements related to social exchanges. Although more research on these areas of treatment is needed, studies demonstrate initial evidence that music may improve skills that could directly affect social skills in children with ASD. ${ }^{34,35,78}$

\section{Conclusion}

Music therapy treatment may be beneficial for improving social skills in children with ASD. The unique qualities of music within therapeutic interventions provide a foundation for practicing social skills, including social engagement and joint attention. Initial evidence supports the use of music therapy intervention for children with ASD, with a 2014 Cochrane review ${ }^{4}$ indicating that music therapy interventions are successful for improving social interaction, verbal communication, initiating behavior, and social-emotional reciprocity.

Although there is research support for the use of music therapy for improving social skills in children with ASD, more research is needed, in particular, on the impact of music therapy on adults with ASD. Furthermore, research is needed on the use of music therapy for children with different comorbidities and different levels of ASD. More research is needed on assessment tools that can appropriately capture social skills in music therapy interventions and the generalization of these skills to other settings. Further, current scales have only indicated parent or clinician perceptions of outcomes, as there are no reports of patients with ASD informing others on their perception of outcomes due to music therapy treatment.

\section{Disclosure}

The author reports no conflicts of interest in this work.

\section{References}

1. Centers for Disease Control and Prevention (CDC) [webpage on the Internet]. Data \& Statistics; 2015. Available from: https://www.cdc.gov/ ncbddd/autism/data.html. Accessed January 16, 2017.

2. American Psychiatric Association. Diagnostic and Statistical Manual of Mental Disorders. 5 ed. Arlington, VA: American Psychiatric Publishing; 2013. 
3. National Autism Center. Findings and Conclusions: National Standards Project, Phase 2. Randolph, MA: National Autism Center; 2015.

4. Geretsegger M, Elefant C, Mossler KA, Gold C. Music therapy for people with autism spectrum disorder. Cochrane Database Syst Rev. 2014;6:CD004381.

5. National Research Council. Educating children with autism. Committee on educational interventions for children with autism. In: Lord C, McGee JP, editors. Division of Behavioral and Social Sciences and Education. Washington, DC: National Academy Press; 2001.

6. Walton KM, Ingersoll BR. Improving social skills in adolescents and adults with autism and severe to profound intellectual disability: a review of the literature. J Autism Dev Disord. 2013;43(3):594-615.

7. Reichow B, Volkmar FR. Social skills interventions for individuals with autism: evaluation for evidence-based practices within a best evidence synthesis framework. J Autism Dev Disord. 2010;40(2):149-166.

8. Reichow B, Steiner AM, Volkmar F. Cochrane review: social skills groups for people aged 6 to 21 with autism spectrum disorders (ASD). Evid Based Child Health. 2013;8(2):266-315.

9. Chang YC, Locke J. A systematic review of peer-mediated interventions for children with autism spectrum disorder. Res Autism Spectr Disord. 2016;27:1-10.

10. American Music Therapy Association [webpage on the Internet]. What Is Music Therapy? 2005. Available from: http://www.musictherapy.org about/quotes/. Accessed December 11, 2016.

11. American Music Therapy Association [webpage on the Internet]. Professional requirements for music therapists. Available from: http://www. musictherapy.org/about/requirements/. Accessed January 16, 2017.

12. American Music Therapy Association. Fact Sheet: Music Therapy and Autism Spectrum Disorder. Silver Spring, MD: American Music Therapy Association; 2015.

13. Thaut M, Hoemberg V, editors. Handbook of Neurologic Music Therapy. New York, NY: Oxford; 2014.

14. Reschke-Hernandez AE. History of music therapy treatment unterventions for children with autism. J Music Ther. 2011;48(2):169-207.

15. Lim HA. Effect of "developmental speech and language training through music" on speech production in children with autism spectrum disorders. J Music Ther. 2010;47(1):2-26.

16. Carpente JA. Investigating the effectiveness of a developmental, individual difference, relationship-based (DIR) improvisational music therapy program on social communication for children with autism spectrum disorder. Music Ther Perspect. 2016.

17. Lim HA, Draper E. The effects of music therapy incorporated with applied behavior analysis verbal behavior approach for children with autism spectrum disorders. J Music Ther. 2011;48(4):532-550.

18. Thompson GA, McFerran KS, Gold C. Family-centred music therapy to promote social engagement in young children with severe autism spectrum disorder: a randomized controlled study. Child Care Health Dev. 2014;40(6):840-852.

19. Walworth DD. The use of music therapy within the SCERTS model for children with autism spectrum disorder. $J$ Music Ther. 2007;44(1): $2-22$.

20. Walworth DD, Register D, Engel JN. Using the SCERTS model assessment tool to identify music therapy goals for clients with autism spectrum disorder. J Music Ther. 2009;46(3):204-216.

21. Kim J, Wigram T, Gold C. The effects of improvisational music therapy on joint attention behaviors in autistic children: a randomized controlled study. J Autism Dev Disord. 2008;38(9):1758-1766.

22. LaGasse AB. Effects of a music therapy group intervention on enhancing social skills in children with autism. J Music Ther. 2014;51(3):250-275.

23. Özdemir E, Norton A, Schlaug G. Shared and distinct neural correlates of singing and speaking. Neuroimage. 2006;33(2):628-635.

24. Peretz I, Zatorre RJ. Brain organization for music processing. Annu Rev Psychol. 2005;56:89-114.

25. Thaut MH, McIntosh GC. How music helps to heal the injured brain: therapeutic use crescendos thanks to advances in brain science. Cerebrum. 2010. Available from: http://dana.org/Cerebrum/2010/How_Music_ Helps_to_Heal_the_Injured_Brain_Therapeutic_Use_Crescendos_ Thanks_to_Advances_in_Brain_Science/. Accessed January 31, 2017.
26. Lai G, Pantazatos SP, Schneider H, Hirsch J. Neural systems for speech and song in autism. Brain. 2012;135(pt 3):961-975.

27. Bonnel A, McAdams S, Smith B, et al. Enhanced pure-tone pitch discrimination among persons with autism but not Asperger syndrome. Neuropsychologia. 2010;48(9):2465-2475.

28. Ouimet T, Foster NE, Tryfon A, Hyde KL. Auditory-musical processing in autism spectrum disorders: a review of behavioral and brain imaging studies. Ann N Y Acad Sci. 2012;1252:325-331.

29. Stanutz S, Wapnick J, Burack J. Pitch discrimination and melodic memory in children with autism spectrum disorder. Autism. 2014;18(2):137-147.

30. Emanuele E, Boso M, Cassola F, et al. Increased dopamine DRD4 receptor mRNA expression in lymphocytes of musicians and autistic individuals: bridging the music-autism connection. Neuro Endocrinol Lett. 2010;31(1):122-125.

31. Gebauer L, Skewes J, Westphael G, Heaton P, Vuust P. Intact brain processing of musical emotions in autism spectrum disorder, but more cognitive load and arousal in happy vs. sad music. Front Neurosci. 2014; 8:192.

32. Robledo J, Donnellan AM, Strandt-Conroy K. An exploration of sensory and movement differences from the perspective of individuals with autism. Front Integr Neurosci. 2012;6:107.

33. Torres EB, Yanovich P, Metaxas DN. Give spontaneity and self-discovery a chance in ASD: spontaneous peripheral limb variability as a proxy to evoke centrally driven intentional acts. Front Integr Neurosci. 2013;7:46.

34. Hardy MW, LaGasse AB. Rhythm, movement, and autism: using rhythmic rehabilitation research as a model for autism. Front Integr Neurosci. 2013;7:19.

35. LaGasse AB, Hardy MW. Considering rhythm for sensorimotor regulation in children with autism spectrum disorders. Music Ther Perspect. 2013;31(1):67-77.

36. Carnahan C, Musti-Rao S, Bailey J. Promoting active engagement in small group learning experiences for students with autism and significant learning needs. Educ Treat Children. 2009;32:37-61.

37. Kim J, Wigram T, Gold C. Emotional, motivational and interpersonal responsiveness of children with autism in improvisational music therapy. Autism. 2009;13(4):389-409.

38. Brownell MD. Musically adapted social stories to modify behaviors in students with autism: four case studies. J Music Ther. 2002;39(2): $117-144$.

39. Fees BS, Kaff M, Holmberg T, Teagarden J, Delreal D. Children's responses to a social story song in three inclusive preschool classrooms: a pilot study. Music Ther Perspect. 2014;32(1):71-77.

40. Kern P, Wolery M, Aldridge D. Use of songs to promote independence in morning greeting routines for young children with autism. J Autism Dev Disord. 2007;37(7):1264-1271.

41. Kern P, Aldridge D. Using embedded music therapy interventions to support outdoor play of young children with autism in an inclusive community-based child care program. J Music Ther. 2006;43(4):270-294.

42. Kaplan RS, Steele AL. An analysis of music therapy program goals and outcomes for clients with diagnoses on the autism spectrum. $J$ Music Ther. 2005;42(1):2-19.

43. Ulfarsdottir L, Erwin P. The influence of music on social cognitive skills. Arts Psychother. 1999;26(2):81-84.

44. Schopler E, Van Bourgondien ME, Wellman GJ, Love SR. Childhood Autism Rating Scale (CARS). 2nd ed. Los Angeles, CA: Western Psychological Services; 2010.

45. Rutter M, LeCouteur A, Lord C. Autism Diagnostic Interview - Revised. Los Angeles: Western Psychological Services; 2008.

46. Lord C, Rutter M, DiLavore P, Risi S. The ADOS-G (Autism Diagnostic Observation Schedule-Generic). Los Angeles: Western Psychological Services; 1999.

47. Thaut M. Assessment and the transformational design model (TDM). In: Thaut M, Hoemberg V, editors. Handbook of Neurologic Music Therapy. New York, NY: Oxford; 2014:60-68.

48. Gfeller K, Davis W. The music therapy treatment process. In: Davis W, Gfeller K, Thaut M, editors. Introduction to Music Therapy: Theory and Practice. 3rd ed. Silver Spring, MD: American Music Therapy Association; 2008:429-486. 
49. Wigram T, Gold C. Music therapy in the assessment and treatment of autistic spectrum disorder: clinical application and research evidence. Child Care Health Dev. 2006;32(5):535-542.

50. Bergmann T, Sappok T, Diefenbacher A, et al. Music-based autism diagnostics (MUSAD) - a newly developed diagnostic measure for adults with intellectual developmental disabilities suspected of autism. Res Dev Disabil. 2015;43-44:123-135.

51.Bergmann T, Sappok T, Diefenbacher A, Dziobek I. Music in diagnostics: using musical interactional settings for diagnosing autism in adults with intellectual developmental disabilities. Nordic J Music Ther. 2016:25(4).

52. Carpente JA. Individual music-centered assessment profile for neurodevelopmental disorders (IMCAP-ND): new developments in musiccentered evaluation. Music Ther Perspect. 2014;32(1):56-60.

53. Constantino JN, Gruber CP. Social Responsiveness Scale. Los Angeles, CA: Western Psychological Services; 2005.

54. Rimland B, Edelson M. Autism Treatment Evaluation Checklist. San Diego, CA: Autism Research Institute; 1999. Available from: https:// www.autism.com/ind_atec. Accessed January 31, 2017.

55. Sparrow S, Balla D, Cicchetti D. Vineland Social-Emotional Early Childhood Scales Manual. Circle Pines, MN: American Guidance Service; 1998.

56. Gerard AB. Parent-Child Relationship Inventory (PCRI) Manual. 4th ed. Torrance, CA: Western Psychological Services; 1995.

57. Fenson L, Marchman V, Thal D, Dale PS, Reznick JS, Bates E. MacArthur-Bates Communicative Development Inventories: User's guide and technical manual. 2nd ed. Baltimore, MD: Paul H. Brookes Publishing Co.; 2007.

58. Thompson G, McFerran KS. 'We've got a special connection': qualitative analysis of descriptions of change in the parent-child relationship by mothers of young children with autism spectrum disorder. Nordic J Music Ther. 2015;24(1):3-26.

59. Allgood N. Parents' perceptions of family-based group music therapy for children with autism spectrum disorders. Music Ther Perspect. 2005; 23(2):92-99.

60. Boso M, Emanuele E, Minazzi V, Abbamonte M, Politi P. Effect of long-term interactive music therapy on behavior profile and musical skills in young adults with severe autism. J Altern Complement Med. 2007;13(7):709-712.

61. Gattino GS, Riesgo RD, Longo D, Leite JCL, Faccini LS. Effects of relational music therapy on communication of children with autism: a randomized controlled study. Nordic J Music Ther. 2011;20(2):142-154.

62. Cohen IL, Sudhalter V. The PDD Behavior Inventory. Lutz, FL: Psychological Assessment Resources, Inc; 2005.

63. Mundy PDC, Block J, Venezia M, Hogan A, Seibert J. A Manual for the Abridged Early Social Communication Scales (ESCS). Coral Gables, FL: University of Miami; 2003.

64. Vaiouli P, Grimmet K, Ruich LJ. 'Bill is now singing': joint engagement and the emergence of social communication of three young children with autism. Autism. 2015;19(1):73-83.
65. Finnigan E, Starr E. Increasing social responsiveness in a child with autism A comparison of music and non-music interventions. Autism. 2010;14(4):321-348.

66. Oldfield A. Interactive Music Therapy in Child and Family Psychiatry: Clinical Practice, Research and Teaching. London: Jessica Kingsley Publishers; 2006.

67. Guy W, editor. ECDEU assessment manual for psychopharmacology. Rockville, MD: US Department of Health, Education, and Welfare; 1976.

68. Overall JE, Gorham DR. The brief psychiatric rating scale. Psychological Reports. 1962;10:799-812.

69. Heaton P. Pitch memory, labelling and disembedding in autism. J Child Psychol Psychiatry. 2003;44(4):543-551.

70. Heaton P. Assessing musical skills in autistic children who are not savants. Philos Trans R Soc Lond B Biol Sci. 2009;364(1522):1443-1447.

71. Carpente J. Contributions of Nordoff-Robbins Music Therapy within the Developmental, Individual Differences, Relationship (DIR) Based Model in the Treatment of Children with Autism: Four Case Studies [unpublished doctoral dissertation]. Ann Arbor: Temple University; 2009.

72. Carpente J, LaGasse AB. Music therapy for children with autism spectrum disorder. In: Wheeler B, editor. Music Therapy Handbook. New York: Guilford: 2014

73. Greenspan SI, Wieder S. Engaging Autism: Using the Floortime Approach to Help Children Relate, Communicate, and Think. Cambridge, MA: Da Capo Lifelong Books; 2006.

74. Thompson G. Family-centered music therapy in the home environment: promoting interpersonal engagement between children with autism spectrum disorder and their parents. Music Ther Perspect. 2012;30(2):109-116.

75. Vaiouli P. Joint engagement for toddlers at risk with autism: a family, music-therapy intervention. Music Ther Perspect. 2014;32(11):193.

76. Preis J, Amon R, Robinette DS, Rozegar A. Does music matter? The effects of background music on verbal expression and engagement in children with autism spectrum disorders. Music Ther Perspect. 2016; 34(1):106-115.

77. Kalas A. Joint attention responses of children with autism spectrum disorder to simple versus complex music. J Music Ther. 2012;49(4): 430-452.

78. Pasiali V, LaGasse AB, Penn SL. The effect of musical attention control training (MACT) on attention skills of adolescents with neurodevelopmental delays: a pilot study. J Music Ther. 2014;51(4): 333-354.

79. Katagiri J. The effect of background music and song texts on the emotional understanding of children with autism. JMusic Ther. 2009;46(1): 15-31.

80. Geretsegger M, Holck U, Bieleninik L, Gold C. Feasibility of a trial on improvisational music therapy for children with autism spectrum disorder. J Music Ther. 2016;53(2):93-120.
Patient Related Outcome Measures

\section{Publish your work in this journal}

Patient Related Outcome Measures is an international, peer-reviewed, open access journal focusing on treatment outcomes specifically relevant to patients. All aspects of patient care are addressed within the journal and practitioners from all disciplines are invited to submit their work as well as healthcare researchers and patient support groups.
Dovepress

The journal is included in PubMed. The manuscript management system is completely online and includes a very quick and fair peer-review system. Visit http://www.dovepress.com/testimonials.php to read real quotes from published authors. 